\title{
MODERATING EFFECT OF DIFFERENCES IN COACHES' CULTURAL BACKGROUNDS IN THE RELATIONSHIP BETWEEN COACHES' LEADERSHIP STYLE AND ATHLETES' SATISFACTIONS
}

\author{
Mohd Hardi Razali, Wirdati Md. Radzi \& Solha Husin \\ Universiti Malaya, Jalan Universiti, 50603 Kuala Lumpur, Wilayah Persekutuan Kuala Lumpur, \\ Malaysia
}

Jurnal Sains Sukan dan Pendidikan Jasmani 7(2): 90-109, Received: 10 Ocotober 2018, Accepted: 25 November 2018

\begin{abstract}
This study examined the moderating effect of local and foreign coaches in the relationship between coaches leadership styles and athletes satisfaction in a case of high performance athletes in Malaysia $(N=350)$ under the organization of Majlis Sukan Negara. Five domains of leadership style showed positive correlation with athletes' satisfaction $(p<.05)$; Training and instruction, $r$ $=0.623$, Democratic, $r=0.500$, Autocratic, $r=0.126$, Social support, $r=0.540$ and Positive feedback, $r=0.490$.There is a significant different of autocratic leadership style and gender $(p<$ .05) Female perceived coaches' autocratic leadership style greater than male. However, in athletes satisfaction, there is no significant different between gender $(p>.05)$. In comparing age groups, there is a significant different in training and instruction leadership style and athletes; satisfaction $(p<.05)$. Age group of $24-26$ years old perceived training and instruction and athletes' satisfaction greater among all age groups. The lowest athletes' satisfaction was group 18-20 years old. On coaches' nationality, training and instruction and athletes' satisfaction also show significant different $(p<.05)$. Foreign coaches exhibit greater training and instruction style than the locals. On the other hand, the athletes satisfied greater to the local coaches' compare to the foreign coaches. Significant correlations were observed between all leadership styles domains and athletes' satisfaction $(p<.05)$ except for autocratic in both local and foreign coaches. This study is expected to extend the body of knowledge of leadership in sport where the cultural differences has never been investigated as the moderating effect in the relationship between coaches' leadership styles and athletes' satisfaction and to improve the quality of coaching by suggesting appropriate strategies to be designed in order to control the effects of cultural differences.
\end{abstract}

Keywords: Leadership style, athletes' satisfaction, foreign and local coaches 


\section{INTRODUCTION}

As a developing nation, progress in various industries and fields within Malaysia is constantly revolving to improve and succeed in each individual sector. Sports development needs to go hand in hand with a country's development. In the Asian region, Malaysia has reserved a place as one of the competitive nations taking part in international multi-sports events such as the Asian Games, ASEAN University Games, Commonwealth and Olympics. Malaysia has championed in various sports discipline namely sailing, gymnastics, shooting, archery, badminton, cycling and diving. It is important to continue the sporting legacy and perform at their very best not only to win, but also to prove to the world that Malaysia is on par with the other developing nations. These sports have contributed gold medals to our country. It is hope that the number of medals will be increased in future. Hence, sports research and development should not be taken lightly, as these will ensure that the sports field continues to improve. Sports organizations remain the axis where most of the actions and underground work of these goals take place.

There is a cliché that says "a coach can make or break an athlete". It is also not uncommon for victorious athletes to cite their coaches as a vital reason for their athletic achievements. Our top squash player, Dato' Nicol David always recites her coach Liz Irving who is an Australian is her best coach who help her to win various tournaments. Coaches help to improve and guide athletes from basic preparation to more specialized physical, technical, tactical and psychological preparation (Nazarudin, Fauzee, Jamalis, Geok, \& Din, 2009). Previous studies have shown that effective coaches lead to satisfied athletes (Kidane, Reddy \& Babu, 2013; Mohamad Nizam, MohdSofian, Jamalis, Soh \& Anuar, 2009; Asiah \& Rosli, 2009), and satisfied athletes are likely to perform well in their sports competitions (Patterson, Carron \& Loughead, 2005; Nazarudin, 2009; Eys, Hardi, Carron \& Beauchamp, 2003; Eichas \& Krane, 1993).

Successful sports dependent on a successful coach. Coaches are described as the key initiator to a team's success. The most important role of a successful coach is to help athletes improve their athletic skills in a wide range of tasks from the sequential developmental movements of a beginner, to the more specialized physical, technical, tactical and psychological preparation of an elite athlete. In general, coaches aim to maximize the performance of athletes and some coaches are known for their ability to achieve this desired outcome and be successful (Reddy, Babu $\&$ Kidane, 2013). Coaches also play a role to identify, plan and implementing suitable training programs for the team. These required a complex task and the use of different strategies and behaviors to fulfill many expectations (Lim, Nor Idayu, Khor \& Radliyana, 2013). They are also indirectly leaders of a team, or a group of individual athletes training under the same coach. Coaches act as team leader by giving skills and confidence to the athletes so that they are competitive in competitions. This means the coaches' leadership style could influence the athletes' performance and developing teams (Patterson, Carron \& Loughead, 2005). Since 1978, Chelladurai and Carron agreed that sport performance would be positively affected if coaches adapted their behaviors to comply with athletes' preferences. Hence, the sports and coaches acts as a team itself, where the relationship is mutual and is not one sided. Coaches therefore play 
significant role in determining the success of athletes' achievement in sports. Recognizing the significant role of coaches in the performance of athletes, our country takes coaching matters very seriously. Qualified coaches with reputable backgrounds are hired and recruited in various sports (eg; aquatics, squash, badminton).

Depending on the nature of the relationship, athletes will find their competitive edge to boost their performance. The issue of leadership styles and athletes 'satisfaction level have been the topic of interest since the early 90s. Chelladurai and Riemer (1997) defined athletes' satisfaction as a positive affective state resulting from a complex evaluation of structures, processes and outcomes associated with the athletic experience. Thus, Kenow and Williams (1999) suggested that if an athlete's goals and beliefs were consistent with that of the coach, a resulting satisfactory interaction between coaches and athletes would occur. However, in Malaysia, the lack of research in sports development is deemed as an impediment for better understanding the complex nature of sports development and success; hence any effort to improve sports performance would be in vain without any clear understanding of the subject matter. Furthermore, researchers have shown that the type of leadership style implement by coaches can have a significant effect on the performance and psychological well-being of the athletes' satisfaction (Kidane, Reddy \& Babu, 2013). A local study conducted by Mohamad Nizam, Mohd Sofian, Jamalis, Soh and Anuar (2009) found that athletes in universities basketball team were likely to be more satisfied with their performance when their coaches has great social consideration. The athletes also preferred their coaches emphasized training and instruction leadership style. Another study conducted locally also examined that universities athletes preferred training and instruction from their coaches and there was correlation between leadership style and athletes' satisfaction (Asiah \& Rosli, 2009).

However, comparing the local and foreign coaches perceived leadership style is scarce in literature. It is well known that Malaysia is hiring some foreign coach to coach some of significant sports to the country, such as aquatics and athletics. Malaysia has some world class athletes, especially in badminton (Dato' Lee Chong Wei), diving (Pandalela Rinong), and squash (Dato' Nicole Ann David) but sport organization face some difficulties to maintain such respectable position due to incompetence coaches (Lim, Nor Idayu, Khor \& Radzliyana, 2013). This very study also stated that local coaches were not confident enough to train sportsmen at states and country level and it's been supported by the Olympic Council of Malaysia secretary that Malaysia should start with training the respective coaches in order to bring back the sports culture in Malaysia. In addition by Ayub (2009), athletes should be trained by the coaches who have expertise in guiding them to achieve the highest performance. Nowadays, Malaysian' coaches' lack of expertise causes high dependency on foreign coaches. As been discussed by Jung and Avolio (1999) same coaching behavior can be perceived differently and can have different effects on satisfaction for athletes from different cultural groups. Hofstede's cultural theory stated that an individual's value is from his/her culture. Thus, it is an interest to study this relationship where it indirectly leads to the present study on assessing the athletes' perception as they are coached by local and foreign coaches from different countries and culture. 
Therefore, comparing the perception of high performance athletes should be at importance as a person's evaluation might be dependent on the culture of his/her coaches' nationality. The athletes' value might be different as they are from various cultural backgrounds. The background of the coaches also might influence athletes' perception towards them. As been proposed by Hofstede's cultural dimensions theory (Hofstede, 2011), the Asian were reported to displayed power distance index which means the society accept the hierarchical system, where they follow the leader instruction and may refrain from expressing disagreement with activities or decision (Hofstede, 2011). With this very knowledge, there is a need to examine the perceived leadership style of local and foreign coaches and the athletes' satisfaction to a huge scope which is among Malaysian high performance athletes that then may serve as foundation for practical action and future research.

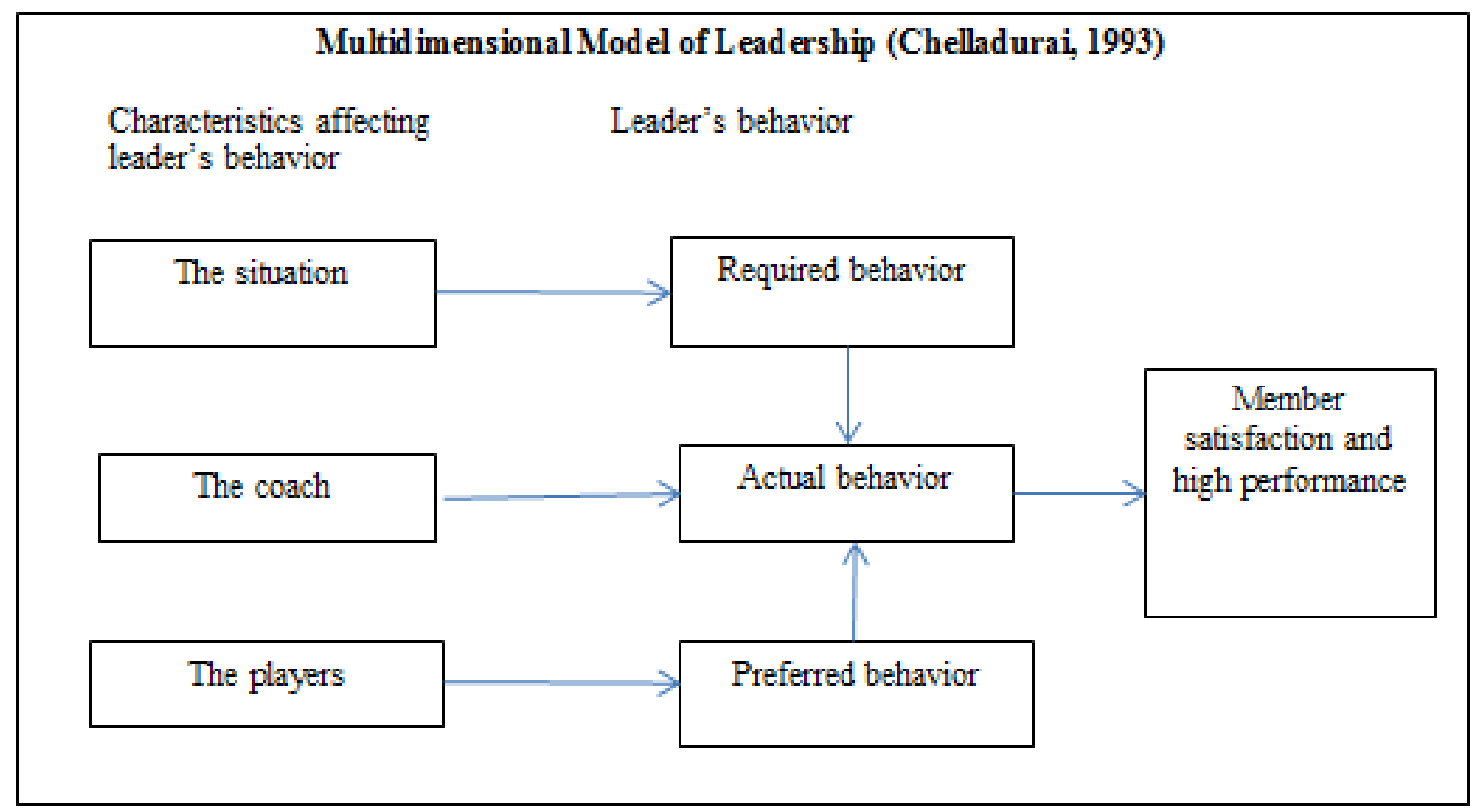

Figure 1. Multidimensional Model of Leadership (Chelladurai, 1993)

\section{LITERATURE REVIEW}

Along the decades satisfaction was always measured in job setting. It has been a source of interest and concern since 1976 (Locke, 1976; Hardman, 1996, Spector, 1997, Profitt, 1990; Mckee, 1991; Evans, 1999; Tobias, 1999; Altman, 2002; Roberts, 2001). Job satisfaction is the emotional satisfaction resulting from one's job experience (Locke, 1976). The construct of satisfaction has also interest researchers and practitioners in the domain of athletics (Riemer \& Chelladurai, 1998). For many coaches, satisfaction and performance are mutually linked. A satisfied athlete is seen as a prerequisite to athlete performing at the highest level. In the ASQ instrument, team and individual performance satisfaction is one of the dimensions measured. Studies have shown that athletes with 
high satisfaction correlate with coaches' motivational state and in turn the motivational state of the group is the ultimate basis of performance effectiveness (House, 1971).

A study conducted by Theodorakis and Bebetso (2003) on team handball athletes found that the athletes were satisfied with their leader's behaviour and performance outcomes. This study was using Athlete Satisfaction Questionnaire (ASQ) in Greece. Gender revealed no significant difference in determining satisfaction. With more practices per week in which the athletes were engaged, the more satisfied they were. This mirrored that the coaches' behavior might affect the athletes satisfaction as they were comfortable with practices. Coaching behavior always related to athlete satisfaction (Reddy, Babu \& Kidane, 2013). Chelladurai's Multidimensional Model of Leadership (1993) states that there are three factors that affect leader behaviour; situational characteristics, leader characteristics and group member characteristics. He also maintained that there are three types of leader behaviour; required behaviour, actual behaviour and preferred behaviour. Required behaviour is what the situation requires the leader to do, actual behaviour is what the leader actually does, which depends upon the above characteristics and preferred behaviour is what the team members want the leader to do. According to this model, it is important for leaders to be flexible depending upon the demands of each situation. When these aspects are harmonious, it should result in desirable performance outcomes and athletes' satisfaction. This statement is proven in various studies (Nazarudin, 2009; Chih, Hui \& Hsuan, 2008; Eys, Hardi, Carron \& Beauchamp, 2003; Eichas \& Krane, 1993).

Leadership is a process by which one person influences the thoughts, attitudes, and behaviours of others (Mills, 2005).In getting a clearer understanding of leadership in sports and the relationship between leadership and other variables, in this case, athletes' satisfaction, the Leadership Scale for Sport (LSS) was used. Chelladurai and Salleh (1980) came out earlier with the Leadership Scale for Sport (LSS) to measure the coaches' leadership behaviour.The instrument consists of five subscales measuring; Democratic and Autocratic style (coach decision-making style), Social Support and Positive Feedback (the coach's motivational tendencies) and Training and Instruction (The coach's instructional behaviour). Most researches conducted with the LSS have focused on the relationship between satisfaction and leadership behaviour, which supported for Chelladurai's model. Many instruments are designed to measure a coach' behaviour; Coaching behaviour Assessment System (Smith, Smoll \& Hunt, 1977), and Decision Style Questionnaire (Chelladurai \& Arnot, 1985). These instruments have also been used to assess athletes' perceptions on their coach's behaviour (Horn, 2002). However, the prominent to use in this present study is LSS.

Relationship between the two variables, leadership and satisfaction was conducted in women population studied by Khalaj, Khabiri and Sajjadi (2011). Chelladurai (2008) stated that sportswomen's satisfaction should be part of sport programs evaluation led to this particular study. The study hypothesized that there were significant relationships between the LSS dimension and ASQ dimension. The highest correlation was training and instruction and individual performance satisfaction, while the lowest correlation was democratic behaviour and individual performance satisfaction. Individual performance satisfaction also exhibited the greatest in a study conducted 
in Ethiopian soccer team (Kidane, Reddy \&Babu, 2013). The study assessing on age group and experience towards the athletes' satisfaction found that youngest athletes (20 years and below) with fewest year of experience satisfied greater in training and instruction of the coaches. The youngest athletes were also least satisfied with their current performance, the same goes to those with longest year of experience.

Training and instruction leadership style was the most preferred by athletes (Khalaj, et al., 2011; Mohd Nizam, et al., 2009; Kidane, et al., 2013.; Asiah \& Rosli, 2009; Lim, 1995) especially on team sports (Chelladurai \& Salleh, 1978). Closed-sport athletes also reported to prefer this leadership style than did the open-sport athletes. Most coaches implemented this leadership style to their athletes. Even so, revisions of the LSS have been produced and used by researchers. For example the Revised Leadership Scale for Sports (RLSS) by Zhang, Jensen and Mann (1997) was used by Mohamad Nizam, et al., (2009) on coaches leadership styles and basketball players' satisfaction. All five leadership styles were correlated significantly with athlete satisfaction. The highest correlation with the athletes' satisfaction was social consideration and the lowest was democratic style. The athletes' satisfaction was the highest in team integration. The study indicated that a considerate coach will results in high satisfaction of the athletes. Democratics was the least preferred followed by autocratic style. Similar result reported by Asiah and Rosli (2009), which were also using the revised version found all the LSS dimension significantly correlated with athletes satisfaction. The greater the coach's social consideration, the highly satisfied the athletes. Team integration showed the highest rating in the study with the least rated was external agents. In contrast with a local study by Aminuddin (2002), he found that transformational leadership behaviour was significantly correlated to athletes' satisfaction. Transformational leaders are characterized by behaviours such as promoting ideas, acts as role models, show care and concern for their subordinates and inspire them by creating visions and challenging them to achieve their goals (Bass, 1998). The study was using soccer and netball athletes from Malaysian high school. They indicated that the athletes were more likely to be satisfied with their performance if they were in good academic standing and had a Malaysian coach. This highlights that having a local coach influenced athletes' satisfaction.

Participative leadership (Democratic) involves the leader including one or more employees on the decision making process. However the leader maintains the final decision making authority (Bass, 1990). In addition when participative leader makes decisions, he or she will decide in collaboration with group members and always use 'majority' as a decision (Bass, 1990). Hirokawa, (1981) mentioned that collaboration decision making as 'Bottom up decision making' which leadership style that made employees feel valuable. There were several benefits that might be obtained through participative leadership styles, which are higher decision making quality, higher decision acceptance by employees, more satisfaction and more effort to improve decision making process (Wu, 2006). However, in athletes studies, democratic did not seem the favour in leadership setting. In a study by Yeganeh, Mohammad Khosravi and Mohammad Bagher (2014) recently has found that democratic style were the least used by the coaches after autocratic style. This study was using wrestlers as the participants and held in Iran, the middle-east countries. The local study 
in Malaysia conducted by Asiah \& Rosli (2009) also reported similar results, where democratic style was the least preferred after autocratic style. Also study in Iran by Khalaj et al., (2011), democratic was the least preferred followed by autocratic leadership style. Even different countries with different culture background, the athletes perceived similar thought on their coaches' leadership style. Interesting agenda can be observed here. Interestingly, democratic behaviour is preferable in individual sport (Schliesman, 1987). Autocratic leaders are leaders that tell his or her employees what he wants done and how he wants it to be done, without getting the advice of his followers (Bass, 1990). In addition, Hofstede (2001) said that decision making is fully made by leaders. In sport setting, autocratic leadership style reported the least preferred by the athletes (Asiah \& Rosli, 2009; Mohamad Nizam et al., 2009). It was found that training and instruction was the most preferred, less on democratic and autocratic behaviour, while positive feedback and social support were still preferable in low key. The studies examining LSS and ASQ have been conducted in many background cultures; from local to abroad studies. Different culture background might perceive in different way (Hofstede, 2010). Thus, difference culture of the athletes should be at importance to be evaluated in this study.

Culture is the collective programming of the mind that distinguishes the members of one group or category of people from others (Hofstede, 2010). According to Hofstede's cultural dimension theory, individual perception might be influenced by their culture. This theory discussed four main dimensions to capture culture.

\section{Power Distance Index}

It is the extent to which the less powerful members of organizations and institutions (like family) accept and expect that power is distributed unequally. This is largely exhibit in Asian countries, where in this society, parents teach children obedience, while small power distance society parents treat children as equals. Those individual in high power distance background may refrain from expressing disagreement with goals or activities, even if they do not plan to implement suggested goals in the long term. The individual view his/her superior as the expert and expect him/her to direct and doing interventions. In the current study, the superior is the coach.

\section{Masculinity-Femininity}

This cultural dimension is refers to distribution of roles and values between the genders. The women in feminine countries have the same modest, caring values as the men; in the masculine countries they are somewhat assertive and competitive, but not as much as men, so that these countries show a gap between men's values and women's values.

\section{Individualism/Collectivism}

Individualism on the one side versus its opposite, Collectivism, as a society, not an individual characteristic, is the degree to which people in a society are integrated into groups. On the individualist side, we find cultures in which the ties between individuals are loose: everyone is expected to look after him/herself and his/her immediate family. On the collectivist side, we find, 
cultures in which people from birth onwards are integrated into strong, cohesive in-groups, often extended families (with uncles, aunts and grandparents) that continue protecting them in exchange for unquestioning loyalty, and oppose other in groups.

\section{Uncertainty avoidance}

Uncertainty Avoidance is not the same as risk avoidance; it deals with a society's tolerance for ambiguity. It indicates to what extent a culture programs its members to feel either uncomfortable or comfortable in unstructured situations. Unstructured situations are novel, unknown, surprising, and different from usual. Uncertainty avoiding cultures try to minimize the possibility of such situations by strict behavioral codes, laws and rules, disapproval of deviant opinions, and a belief in absolute Truth; 'there can only be one Truth and we have it'.

By understanding the cultural study, it will lead to different way of thought and perception. If one perceived others behaviour as the preferred one, in return will results in satisfaction. If the athletes perceived their preferred behaviour of their coaches and satisfies with it, performance is predicted in high state. When satisfaction takes place, high performance will results. Thus, Hofstede's theory is the best in explaining the need of cultural study on understanding the thought and perception of an individual.

\section{Model of Coaching Effectiveness Behavior (Horn, 2002)}

This theory explaining on how coach behaviour affect athletes behaviour. Proposed by Horn (2002), he came out with several points in discussing the link of this theory to coach-athlete relationship.

First point: Athletes are influenced by their coaches, both cognitively and behaviourally. Horn's model recognizes the sociocultural context, the organizational climate, and the coaches' personal characteristics as antecedents of the coaches' behaviour. These three antecedents affect the coaches' behaviour via the coaches' own formulated values, belief and expectancies of the team.

Second point: Focus on the effect of coaches' behaviour on the athletes' performance and behaviour. In this present study (correlation of leadership style and athletes' satisfaction), it is hypothesized that coaches' behaviour affect the athletes' performance. This model also theorized relationship between the way coach behaves in practice and competitive contexts and the athletes' performance and behaviour. It is also proposes that there are certain aspects of coaches' behaviour that have a direct effect on athletes' performance and behaviour. When the athletes perceived the coach's behaviour in a different way, in return, this influences each athlete's self-perception, performance and behaviour differently.

Third point: This model examines the indirect relationship between coaches' behaviours and performance by recognizing that coaches' effectiveness in the sport domain is mediated by differences in both situational and individual variables. Not only does each individual athlete perceive and interpret his/her coaches' behaviour differently, but the effectiveness of different types of coaching behaviors also varies according to the sport (eg; skill, age) and athletes' 
variables. As the model shows, athletes' interpretation of their coaches' behavior is also mediated by the antecedent factors of sociocultural context, organizational climate and personal characteristics (eg; age, gender, traits). Ultimately this shows that affective coaching is determined by the individual and is a function of individual attributes, such as sport and personal characteristics.

Given that the current research study focuses on the link between high performance athletes' perception on their coaches' leadership style (behaviour) and their satisfaction, thus this model appropriate to theorized the findings later on.

\section{METHODS}

Cross-sectional research design was employed in this study in order to gather information on a population at a single point in time (Baumgartner, Strong \& Hensley, 2006). This quantitative type correlation study utilizes the survey method. The population for this study consisted of high performance athletes who are currently funded by Majlis Sukan Negara Malaysia. A total of 350 athletes served as participants in this study. They were selected from athletes who participated in both individual and team sports through purposive sampling. The estimated population of high performance athletes funded by Majlis Sukan Negara is 1200 (Majlis Sukan Negara, 2015). Based on Krejcie and Morgan (1970), for 95\% of confidence intervals, sufficient sample size is 291 participants. However, 350 high performance athletes will be involved in this study as the precaution of missing and incomplete data. The amount of 350 athletes was according to $20 \%$ of return rate (Baumgartner, Strong, \& Hensley, 2006). In this study, only athletes who represent Malaysia at international level were selected.

The Leadership Scale for Sport (LSS) was used to evaluate the athletes' perception of their coaches' leadership style. It was developed by Chelladurai and Salleh (1980). The reliability and validity of this questionnaire have been established (Gastel, 2008). It is consisted of 40 items based on 5 dimensions; training and instruction, democratic behavior, autocratic behavior, social support, and positive feedback. Each item was scored using the 5-point Likert scale, from Never to Always. All items were summed up and averaged for each dimension. These five dimensions of leader behavior were defined by Chelladurai (Chelladurai, 1990).

On the other hand, the athletes' satisfaction was assessed using the Athletes Satisfaction Questionniare (ASQ) which comprises of 56 items. This instrument was developed by Chelladurai and Riemer (1998). The reliability and validity of this questionnaire have been established, $\alpha=.78$ - .95 (Riemer \& Chelladurai, 1998). Each item in this instrument was scored using the 5-point Likert scale from extremely not satisfied to very satisfy.

The data were analyzed using Statistical Package for Social Sciences (SPSS) version 21.0. Descriptive statistics for all variables were presented as frequencies, means \pm standard deviation $(M \pm S D)$ and percentages. Independent sample t-test was conducted to examine the difference of variables between gender and coaches' nationality, while one way analysis of variance (ANOVA) were conducted to examine the difference of variables between age groups. Pearson's correlation 
tests were used to determine the relationships between perceived leadership style of local and foreign coaches and athletes' satisfaction. The significant level was set at .05 $(p<.05)$.

\section{RESULTS}

A total of 350 national athletes participated in this study, which consists of $53.4 \%$ male and $46.6 \%$ female aged from 18 to 26 years old. Local coaches were $51.1 \%$ while foreign coaches were $48.9 \%$.

The results shown in Table 1 indicates that autocratic was significantly different between male and female; male $=3.067 \pm 0.998$, female $=4.038 \pm 0.674(p<.05)$. The female athletes perceived their coaches apply autocratic style greater than male athletes. The other four leadership styles were not significant different between male and female $(p>.05)$.

In comparing the leadership styles by age group (Table 2), training and instruction show a significant difference between age groups; $18-20$ years old $=4.006 \pm 0.580,21-23$ years old $=$ $4.100 \pm 0.864,24-26$ years old $=4.188 \pm 0.461$, and 27 years old and above $=3.786 \pm 0.934(\mathrm{p}<$ $.05)$. Age group $24-26$ years old shows the highest perceived autocratic leadership style of their coaches and the lowest was age group 27 years old and above.

Table 1. Comparison of leadership styles between gender

\begin{tabular}{lccc}
\hline \multirow{2}{*}{ Leadership style } & \multicolumn{2}{c}{$M \pm S D$} & \\
\cline { 2 - 3 } Training \& instruction & $3.989 \pm 0.760$ & $3.984 \pm 0.854$ & .527 \\
\hline Autocratic & $3.067 \pm 0.998$ & $4.038 \pm 0.674$ & $.06^{*}$ \\
\hline Democratic & $3.980 \pm 0.898$ & $2.784 \pm 0.896$ & .967 \\
\hline Positive & $3.764 \pm 0.805$ & $3.568 \pm 0.780$ & .371 \\
\hline Social & $3.668 \pm 0.733$ & $3.685 \pm 0.842$ & .216 \\
\hline
\end{tabular}

*significant level is at $.05(p<.05)$.

Table 2. Comparison of leadership styles by age group

\begin{tabular}{|c|c|c|c|c|c|}
\hline \multirow{3}{*}{ Leadership style } & \multicolumn{4}{|c|}{$M \pm S D$} & \multirow{3}{*}{$p$-value } \\
\hline & \multicolumn{4}{|c|}{ Age (years) } & \\
\hline & $18-20$ & $21-23$ & $24-26$ & $>27$ & \\
\hline $\begin{array}{l}\text { Training \& } \\
\text { instruction }\end{array}$ & $4.006 \pm 0.580$ & $4.100 \pm 0.864$ & $4.188 \pm 0.461$ & $3.786 \pm 0.934$ & $.016^{*}$ \\
\hline Autocratic & $3.946 \pm 0.882$ & $4.100 \pm 0.992$ & $4.157 \pm 0.686$ & $3.794 \pm 0.958$ & .345 \\
\hline Democratic & $2.930 \pm 0.939$ & $2.998 \pm 1.046$ & $3.077 \pm 0.736$ & $2.765 \pm 1.046$ & .091 \\
\hline Positive & $3.540 \pm 0.700$ & $3.726 \pm 0.803$ & $3.723 \pm 0.579$ & $3.619 \pm 0.925$ & .410 \\
\hline Social & $3.683 \pm 0.774$ & $3.856 \pm 0.849$ & $3.753 \pm 0.589$ & $3.657 \pm 1.032$ & .239 \\
\hline
\end{tabular}

*significant level is at $.05(p<.05)$. 
Table 3 shows that there is no significant different of athletes' satisfaction between male and female $(\mathrm{p}>.05)$.

Table 3. Comparison of athletes' satisfaction by gender

\begin{tabular}{lccc}
\hline & \multicolumn{2}{c}{ Mean \pm SD } & \\
\cline { 2 - 3 } & Male & Female & $p$-value \\
\hline Athletes' satisfaction & $3.989 \pm 0.760$ & $3.984 \pm 0.854$ & .527 \\
\hline
\end{tabular}

*significant level is at $.05(\mathrm{p}<.05)$.

There is a significant different of athletes' satisfaction between age groups; $18-20$ years old $=4.953 \pm 0.891,21-23$ years old $=5.285 \pm 1.024,24-26$ years old $=5.322 \pm 0.902$, and 27 years old and above $=5.105 \pm 0.906(\mathrm{p}<.05)($ Table 4$)$. Age group $24-26$ years old shows the highest athletes' satisfaction and the lowest was age group $18-20$ years old. Table 4 shows the result.

Table 4. Comparison of athletes' satisfaction by age group

\begin{tabular}{ccc}
\hline $\begin{array}{c}\text { Age group } \\
\text { (years) }\end{array}$ & $M \pm S D$ & $p$-value \\
\hline $18-20$ & $4.953 \pm .891$ & $.015^{*}$ \\
$21-23$ & $5.285 \pm 1.024$ & \\
$24-26$ & $5.322 \pm .902$ & \\
$>26$ & $5.105 \pm .906$ & \\
\hline
\end{tabular}

*significant level is at $.05(\mathrm{p}<.05)$.

Table 5 shows the difference of perceived leadership style of coaches between coaches' nationality. Training and instruction show a significant difference between local and foreign coaches; local $=3.93 \pm .744$ and foreign $=4.096 \pm .687(p<.05)$. The other leadership styles were not significant $(p>0.5)$.

Table 5. Comparison of perceived leadership style by coaches' nationality

\begin{tabular}{lccc}
\hline \multirow{2}{*}{ Leadership style } & \multicolumn{2}{c}{ Mean $\pm S D$} & \multirow{2}{c}{ Coaches' nationality } \\
\cline { 2 - 3 } & \multicolumn{2}{c}{ Local } & \\
\cline { 2 - 3 } $\begin{array}{l}\text { Training \& } \\
\text { instruction }\end{array}$ & $3.93 \pm .744$ & $4.096 \pm .687$ & $.033^{*}$ \\
& & & \\
Autocratic & $2.988 \pm .973$ & $2.882 \pm .949$ & .309 \\
Democratic & $4.052 \pm .897$ & $3.907 \pm .852$ & .120 \\
Positive & $3.712 \pm .771$ & $3.743 \pm .874$ & .725 \\
Social & $3.631 \pm .727$ & $3.611 \pm .788$ & .810 \\
\hline
\end{tabular}

*significant level is at $.05(p<.05)$. 
The result shows that there is a significant different of athletes' satisfaction between local and foreign coaches; local $=5.198 \pm .868$ and foreign $=5.007 \pm .936(\mathrm{p}<.05)($ Table 6$)$.

Table 6. Comparison of athletes' satisfaction by coaches' nationality

\begin{tabular}{|c|c|c|c|}
\hline & \multicolumn{2}{|c|}{ Mean \pm SD } & \multirow{3}{*}{ p-value } \\
\hline & \multicolumn{2}{|c|}{ Nationality } & \\
\hline & Local & Foreign & \\
\hline $\begin{array}{l}\text { Athletes' } \\
\text { satisfaction }\end{array}$ & $5.198 \pm .868$ & $5.007 \pm .936$ & $.048 *$ \\
\hline
\end{tabular}

*significant level is at $.05(\mathrm{p}<.05)$.

Pearson correlation analysis was conducted to measure the relationship between leadership styles and athletes' satisfaction (Table 7). There are five domains in leadership styles measured. All of the domains were significant positive correlated with athletes' satisfaction $(p<.05)$.

Table 7. Relationship between leadership styles and athletes' satisfaction

\begin{tabular}{lc}
\hline Leadership style & Correlation $(r$-value $)$ \\
\hline Training \& instruction & $0.623^{*}$ \\
Democratic & $0.500^{*}$ \\
Autocratic & $0.126^{*}$ \\
Social support & $0.540^{*}$ \\
Positive feedback & $0.490^{*}$ \\
\hline
\end{tabular}

*significant level is at $.05(\mathrm{p}<.05)$.

Table 8 represents the correlation between leadership styles and athletes' satisfaction by coaches' nationality. Significant correlations were observed between all leadership styles domains and athletes' satisfaction $(p<.05)$ except for autocratic in both local and foreign coaches. All significant correlations were positive.

Table 8. Correlations between leadership styles and athletes' satisfaction by coaches' nationality

\begin{tabular}{llll}
\hline & \multicolumn{3}{c}{ Nationality } \\
\cline { 2 - 4 } Leadership style & Local & Foreign \\
\cline { 2 - 4 } & & Correlation $(r)$ & \\
\hline Training \& instruction & $.651^{*}$ & $.638^{*}$ \\
Democratic & $.420^{*}$ & $.575^{*}$ \\
Autocratic & .120 & .122 \\
Social support & $.439^{*}$ & $.634^{*}$ \\
Positive feedback & $.445^{*}$ & $.539^{*}$ \\
\hline
\end{tabular}

*significant level is at $.05(p<.05)$. 


\section{DISCUSSION}

Five leadership styles examined shows that female athletes perceived greater autocratic style than male athletes. The other four types of leadership styles show no significant difference between male and female. The female athletes also exhibit that their coaches are more likely practicing an autocratic style and least on democratic style. On the other hand, male athletes perceived their coaches to be more likely into training and instruction and least on autocratic style. Gender differences observed an interesting insight in the current study. Although similar studies (Shaharudin, 2005) indicated that both male and female perceived their coaches to be least likely into autocratic style and more likely into positive feedback, the present study found the other way around. These contradict findings may be due to age difference where the present study involved athletes who aged 18 years and above. The male athletes perceived their coaches were more into training and instruction indicate that they preferred practical training and willing to follow instructions from their coaches. Meanwhile, the female athletes' perceived autocratic style may be due to the coaches implemented a-must-win-and-be-successful so that the athletes will perform in sports. These findings unfollow the path-goal theory (House, 1971). The path-goal theory suggests that coaching and guidance would be provided by the coach if lacking in the environment. Thus, this may explain that the coaches of these athletes are doing their job well.

Training and instruction were observed to be a significant difference between age groups whereby the others did not show significant differences. The older athletes in this study who aged 27 years old and above perceived lesser training and instruction by their coaches, while those who aged between 24 and 26 years old perceived the highest. This reflects that as the athletes grow, their perception towards serious training and willingness to follow instruction from their coaches are greater. As the athletes mature, their experience in sports are greater, thus these coaches practice more on this dimension due to the athletes can receive better in training and able to follow the command given. Few studies support the findings of age factor does give impact to the perception of the athletes' on coaches' leadership styles (Nazarudin et al, 2009).

Athletes' satisfaction is the important antecedent to the theory of coaching behaviour and athletes' performance. The current findings show that in measuring the difference between gender, there was no significant difference. However, in comparing between age groups, there was a significant difference. Age between 24 and 26 years old shows the highest athletes' satisfaction and the lowest was between $18-20$ years old. This may be explained again by the maturity factor of the athletes. Older athletes related to more experience in sport, thus they tend to satisfy greater in athletic view. This finding is in line with Anuar, Salleh and Siti Ajar (2015) where the longer the athlete participates in a sport environment, the more matured the athlete become. A more challenging and intense competition improves the confident level of an athlete.

The present study added its uniqueness where it intends to observe the difference between coaches' nationality of local and foreign on leadership style and athletes; satisfaction. By searching for linkage along these continuums, the researcher anticipated to get a better picture of different nationality of the coaches on the athletes' perception of their leadership styles and satisfaction, as 
well as to predict some of the factors that may be contributing to these two variables measured. Data on the differences between local and foreign coaches and their leadership styles and athletes' satisfaction is not much available in the literature. There was a significant difference between local and foreign coaches in training and instruction. The other four leadership styles exhibited no differences between local and foreign coaches. Therefore, it is viable to conclude that those coaches were practicing these four leadership styles in a similar manner. Hence, none of the leadership styles are influenced by the nationality of the coaches. Foreign coaches were perceived greater in giving training and instruction to the athletes than local coaches. Local coaches exhibited lesser training and instruction style. This gives interesting information to the findings. The foreign coaches in this study were perceived to be greater at improving the athletes' performance by emphasizing and facilitating hard and strenuous training, instructing the athletes' skills, techniques, and tactics in sport, clarify the relationship among the athletes and structuring and coordinating the athletes' activities. In addition, athletes' satisfaction also observed a significant difference between local and foreign coaches. The athletes were satisfied greater to local coaches than foreign coaches. The coaches' cultural background may be the reason for this difference. Culture is the collective programming of the mind that distinguishes the members of one group or category of people from others (Hofstede, 2010). According to Hofstede's cultural dimension theory, individual perception might be influenced by their culture. Thus, this explains the two findings. Difference cultural background may lead to difference leadership style in which in this study for training and instruction and athletes' satisfaction. The athletes satisfied with local coaches, thus the researcher suggests sport performance could benefit from this as it was documented that satisfied athletes would perform better in sport (Nazarudin, 2009; Chih, Hui \& Hsuan, 2008; Eys, Hardi, Carron \& Beauchamp, 2003; Eichas \& Krane, 1993; House, 1971).

The present study revealed the very relationships between coaches' leadership styles and athletes' satisfaction. The variables mentioned in this study point to a positive relationship between all five dimensions of coaches' leadership style and athletes' satisfaction as indicated by other studies (Khalaj, Mohammad Khabiri, \& Sajjadi, 2011; Mohd Nizam, Mohd Sofian, Jamalis \& Soh, 2009; Asiah \& Rosli, 2009) except for autocratic leadership style, which reflects that the greater the athletes' satisfaction, the greater the coaches implementing training and instruction, democratic, social support and positive feedback. The researcher can assume that the athletes were happy with their coaches' leadership styles except for autocratic. The autocratic styles which might involve independence in decision-making and tresses on personal authority did not influence the athletes' satisfaction. The athletes also satisfied greater when their coach make complex things easier to understand and learn, willing to correct athletes' mistake, give explanation to athletes' techniques and tactics in sport, use a variety of drills for a practice, stress the mastery of greater skills, use objective measurement for evaluation, conduct proper progressions in teaching fundamentals, supervise athletes' drills closely, clarify training priorities and work on them, possess good knowledge of the sport, provide feedback after a substitution and provide instructions that are brief, clear and concise. These satisfactions applied to both local and foreign coaches. 


\section{CONCLUSION}

This study was carried out with a purpose to reveal the moderating effect of different cultural background (local and foreign coaches) on the athletes' satisfactions with their coaches' leadership styles. A detailed description of coaches' leadership styles and athletes' satisfaction and their differences on athletes' gender, age groups, and coaches' nationality were the aims of the current study. There was an existence of a relationship between leadership styles and athletes' satisfaction in the context of Malaysian national athletes. The five leadership styles show a positive correlation with athletes' satisfaction. There is a significant different of autocratic leadership style between gender. Female perceived coaches' autocratic leadership style greater than male. However, in athletes satisfaction, there is no significant different between gender. In comparing age groups, there is a significant different in training and instruction leadership style and athletes. Age group of 24 - 26 years old perceived training and instruction and athletes' satisfaction greater among all age groups. The lowest athletes' satisfaction was group 18-20 years old. On coaches' nationality, training and instruction and athletes' satisfaction also show significant differences. These observations revealed that foreign coaches were perceived greater in giving training and instruction to the athletes than local coaches. Local coaches exhibited lesser training and instruction style. Last but not least, significant correlations were observed between all leadership styles domains and athletes' satisfaction except for autocratic in both local and foreign coaches. Overall, the coaches' leadership styles and its relationship with athletes' satisfaction were answered in this study. Comparisons of these variables with coaches' nationality were also discovered. Thus, the hiring of local or foreign coaches for national athletes could be justified based on the findings.

\section{RECOMMENDATION}

Strategies for hiring local or foreign coaches should include measures by the sports setting the standard that coaches should oblige. Sports organizations can advise coaches to adapt certain leadership styles deemed most desirable by the athletes. A coach cannot risk a team's success without considering that his or her athletes also do have expectations and targets, which if met will trigger satisfaction. Satisfaction is what gives the athletes a competitive edge, a feeling of contentment which will drive him or her to train and compete honestly, whole heartedly and giving the very best every time. Coaches can benefit by understanding the importance aspects of leadership styles and their effects on both athletes' satisfaction, and indirectly, their performance. It was evident from this study that less autocratic would benefit the coaches. Therefore, by practicing more on training and instruction in coaching should be considered as the athletes satisfied greater, thus will boost their sports performance.

Given a current body of evidence on the relationships between coaches' leadership styles

and athletes' satisfaction, it is recommended to continue the research into this area. A further study by exploring the gender differences of coaches on the same setting should be carried out. It would 
be beneficial to examine the gender of coach regarding their leadership styles and athletes' satisfaction. Future studies should make a comparison in terms of team sport and individual sports coaches. An interesting finding could be gathered involving the different nature of sport among athletes.

A study on whether the athletes' motivation influences the perceived coaches' leadership styles and their satisfaction should be carried out too. The psychological factors play an important role so that high-performance athletes will keep exposing in sport and indirectly will give optimum performance in competition.

Last but not least, future study should encompass athletes throughout Malaysian universities. Then a researcher can compare the leadership styles of national and collegiate coaches in line to find the standard of leadership style at the national level. Furthermore, by having numbers of collegiate athletes from every university, researchers can compare the athletes' satisfaction between universities and national team.

\section{ACKNOWLEDGMENT}

The authors would like to thank the athletes involved in this study and Majlis Sukan Negara for the cooperation and permission to conduct the study and Sports Centre of Universiti Malaya for the approval in completing this research.

\section{REFERENCES}

Anuar, D., Salleh, A. R. \& Siti Ajar, M. N. (2015). The relationship and influence of coaching leadership style in training program towards students athletes' satisfaction. South-East Asian Journal for Youth, Sports \& Health Education, 1 (1).

Aminuddin, Y. (2002). Practice of transformational leadership among Malaysia high school coaches and its impact on athlete satisfactions with individual performance. Journal of International Council for Health, Physical Education, Recreation, Sport and Dance, 38 (1), 26 - 30.

Asiah, M. P. \& Rosli, S. (2009). Coaching leadership styles and athlete satisfactions among hockey team. Journal of Human Capital Development, 2(1), 77 - 86.

Ayub, H. (2009). The Predicted Factors of Cognitive and Affective Learning at the Level 1 Sports Science Course by the Malaysian National Sports Council. Universiti Putra Malaysia.

Bass, B. M. (1990). Handbook of Leadership. ed.3. New York: Free Press.

Bass, B. M. (1998). Transformational leadership: Industry, military, and educational impact. Mahwah, NJ: Erlbaum

Baumgartner, T. A., Strong, C. H., \& Hensley, L. D. (2006). Conducting and reading research in health and human performance ( $4^{\text {th }}$ ed.). New York: McGraw-Hill

Chelladurai, P. \& Salleh, S. D. (1980). Dimensions of leader behaviour in sports: Development of a leadership scale. Journal of Sport Psychology, 2, 34 - 45.

Chelladurai, P. \& Reimer, H. A. (1998). A classification of facets athlete satisfaction. Journal of Sport Management, 11, $13-159$.

Chelladurai, P. \& Arnot, M. (1985). Decision styles in coaching: preferences of basketball player. Research Quarterly for Exercise and Sport, 56, 15 -24.

Chelladurai, P. (1990). Leadership in sports: a review. International Journal of Sport Psychology, 21, 328-354 
Chelladurai. P. (2008). Management of Human Resources in Sport and Health Entertainments. Publication Center of Ferdowsi University of Mashhad.

Chih, C. C., Hui, T. H., Hsuan, L. K. (2007). A study of Leadership Styles and Team Cohesion in Elite Collegiate Rugby Student- Athlete. Chin-Men Institute of Technology Journal, 2(3), 121-129.

Gastel, V.C. (2008). Leadership scale for sports (LSS). Sportspsyc Unpublished.

Eichas, T. M., Krane, V. (1993). Relationship among perceived leadership style and member satisfaction, and team chosen. Journal of sport science, 20. 219-226

Evans, L. (1999). Teacher morale, job satisfaction and motivation. London: Paul Chapman Publishing.

Eys, M. A., Hardi, J., Carron, A. V., Beauchamp, M. R. (2003). The Relationship between Task Cohesion and Competitive State Anxiety. Journal of Sport and Exercise Psychology, 25 (1).

Hardman, T.M. (1996). A leader behaviour and leadership idealogy of educational administration and aircraft commanders. Harvard Educational Review, 25, 1-32.

Hirokawa, R.Y. (1981) Group problem and problem-solving effectiveness: A critical review of inconsistent findings. Communication Quarterly, 30, 134-141

Hofstede, G. (2001). Culture's Consequences: Comparing Values, Behaviors, Institutions, and Organizations Across Nations. SAGE Publications.

Hofstede, G. (2010). The GLOBE debate: Back to relevance. Journal of International Business Studies, 41, 1339-46.

Hofstede, G. (2011). Dimensionalizing cultures: the Hofstede model in context. Online Readings in Psychology and Culture, 2 (1).

Horn, T. S. (2002). Coaching Effectiveness in sport domain: Advances in sport psychology. Champaign, IL: Human Kinetics.

House, R. J. (1971). A path-goal theory of leader effectiveness. Administrative Science Quarterly, 16, 321 - 338.

Jung, D. I., \& Avolio, B. J. (1999). Effects of leadership style and followers' cultural orientation on performance in group and individual task conditions. Academy of Management Journal, 42, 208- 218.

Khalaj, G., Mohammad Khabiri, \& Nasrollah, S. (2011). The relationship between coaches'leadership styles and player satisfaction in women skate championship. Procedia Social and Behavioral Science, 15, 3596 - 3601.

Kidane, W. W., Reddy, C. \& Babu, S. M. (2013). The effect of coaching behaviour on players' satisfaction in the case of Ethiopian soccer players: review of literature. International Journal of Social Science \& Interdisciplinary Research, 2 (1), $106-117$.

Kenow, L. \& Williams, J. M. (1999). Coach-athlete compatibility and athlete's perception of coaching behaviors. Journal of Sport Behavior, 2, 251

Krejcie, R.V. \& Morgan, D. W. (1970). Determining sample size for research activities. Educational And Psychological Measurement, 30, 607 - 610

Lim, K. C. (1995). Coach leadership behaviours and their relationship to athletes' achievement orientation and satisfaction. Unpublished Master Thesis. Universiti Sains Malaysia.

Lim, K. C., Nor Idayu, M., Khor, P. H. \& Radzliyana, R. (2013). Student-athletes’ perceptions of coaches' competency at the Malaysian Public Institution of Higher Learning. World Journal of Education, 3 (1), 13 -22.

Locke, E. A. (1976). The nature and causes of job satisfaction. In MD. Dunnette (Ed.), Handbook of Industrial and Organization Psychology, Chicago: Rand-McNally, 1297 - 1349.

Majlis Sukan Negara. (2015).

McKee, J.G. (1991). Leadership styles of community college presidents and faculty job satisfaction. Community/ Junior College Quarterly of Research and Practice, 15 (1), 33-46.

Mills, D. Q. (2005).Leadership: How to Lead, How to Live. Waltham, Mass.: MindEdge

Mohammad Nizam, Mohd Sofian, O. F., Jamalis, M., Soh, K. G. \& Anuar, D. (2009). Coaching leadership styles and athlete satisfactions among Malaysian University basketball team. Research Journal of International Studies, $9,4-11$.

Nazarudin, M. N. B. (2009). Coaching Leadership Styles and Athlete Satisfaction among Malaysian University Basketball Team. Research Journal of International Studies, 9, 4-11. 
Patterson, M. M., Carron, A. V. \& Loughead, T. M. (2005). The influence of team norms on the cohesion-self-reported performance relationship: a multi-level analysis. Psychology of Sport and Exercise, 479 - 493.

Profit, A.C. (1990).The relationship between locus of control and job satisfaction of Appalachian principals. Abstract from: Proquest file: Dissertation Abstract International.

Reddy, C., Babu, S. M. \& Kidane, W.W. (2013). The effect of coaching behavior on player's satisfaction in the case of ethiopian soccer players: review of literature. International Journal of Social Science \& Interdisciplinary Research, 2, 1.

Reimer, H. A. \& Chelladurai, P. (1998). Development of Athlete Satisfaction Questionnaire. Journal of Sport \& Exercise Psychology, 20, 127 - 156.

Reimer, H. A. \& Toon, K. (2001). Leadershi and satisfaction in tennis: examination of congruence, gender and ability. Res $Q$ Exerc Sport, 72, 3, 243 - 56.

Roberts, W. (2001). It takes more than a carrot and a stick. New York: Andres McMeel.

Shrivastava, Y. \& Sharma, R. (2015). Leadership behavior as preferred by male athletes of different games and sports. International Journal of Physical Education, Sports and Health, 1, 6, 96-9

Smith, F. T, Smoll, R. E. \& Hunt, E. B. (1977). A system for the behaviour assessment of athletic coaches. Research Quarterly, 48, 401407.

Spector, P.E. (1997). Job satisfaction: application, assessment, cause and consequences. California:Sage Publishers.

Schliesman, E. S. (1987). Relationship between the congruence of preferred and actual leader behavior and subordinate satisfaction with leadership. Journal of Sport Behavior, 10, 157-166.

Shaharudin, A. A. (2005). Perkaitan antara matlamat dan stail kepimpinan dengan pencapaian atlet SUKMA Negeri Perak di Kejohanan SUKMA 2004. eWacanaPenyelidikan UPSI, 13.

Theodorakis, N. \& Bebetsos, E. (2003). Examination of athletes' satisfaction: a first approach. Inquiries in Sport and Physical Education, 1, 197 - 203.

Tobias, C.U. (1999). The way we work. Tennessee: Broadman\& Holman.

Wu, M. Y. (2006). Compare participative leadership in three cultures. China Media research, 2(3), 19-30.

Yeganeh, S., Mohammad Khosravi, G. \& Mohammad Bagher, F. O. (2014). Relationship between leadership styles of trainers with satisfaction wrestling. International Journal of Sport Studies, 4(2), 218 - 224.

Zhang, J., Jensen, B. E. \& Mann, L. (1997). Modification and revision of the leadership scale for sport. Journal of Sport Behavior, 20 (1), $105-122$.

\author{
ఏ. Mohd Hardi Razali \\ Sports Centre, \\ Universiti Malaya, \\ Jalan Universiti, 50603 Kuala Lumpur, \\ Wilayah Persekutuan Kuala Lumpur, Malaysia \\ Email: mohdhardirazali@gmail.com
}

